\title{
La historicidad del delito en la manualística del derecho penal colombiano*
}

\section{The Historicity of Crime in the Handbooks of Colombian Criminal Law}

Gilberto Enrique Parada-Garcia a

Universidad del Tolima, Colombia

geparadag@ut.edu.co

ORCID: http://orcid.org/0000-0002-7832-9733
DOI: https://doi.org/10.11144/Javeriana.vj137.hdmp Redalyc: http://www.redalyc.org/articulo.oa $? \mathrm{id}=82556549010$

Fecha de recepción: 13 Junio 2017

Fecha de aprobación: 20 Marzo 2018

Fecha de publicación: 30 Noviembre 2018

\section{Resumen:}

Esta investigación evidencia cómo la noción concebida por el derecho penal sobre la historia del delito ha sido un recurso residual a la hora de comprender científicamente el delito. El artículo analiza las referencias a la historia del delito que aparecen en los manuales de derecho penal publicados en el medio colombiano desde siglo XIX hasta el presente. También se incluyen en esta indagación algunas monografías, tesis y cursos de derecho penal que exponen contenidos similares de la historicidad del crimen en Colombia. A partir de una perspectiva metodológica crítica, el texto destaca cómo los conceptos de la evolución, el apego al formalismo y al legalismo, y la continuidad de modelos pedagógicos tradicionales han configurado una noción de historia del delito que fue plasmada por esta manualística del derecho penal y que difiere en gran medida de otras historiografías del delito. Se confirma entonces que la historicidad del delito y la noción del tiempo histórico, a través del cual se ha interpretado el pasado del derecho penal, han sido condicionadas por determinismos y reduccionismos que se compaginaron muy bien con la dogmática del derecho penal.

Palabras clave: Historicidad del delito, manualística del derecho penal, evolución, pedagogía.

\begin{abstract}
:
The research shows how the notion conceived by criminal law on the history of crime has been a residual resource when it comes to scientifically understanding crime. The article analyzes the references to the history of crime that appear in the handbooks of criminal law published in the Colombian milieu from the 19th Century until the present moment. Also, in this investigation are included monographs, theses and courses of criminal law that expose similar contents of the crime's historicity in Colombia. From a critical methodological perspective, the text highlights how the concepts of evolution, the attachment to formalism and legalism, as well as the continuity of traditional pedagogical models, have shaped a notion of crime history that was embodied in this handbooks of Criminal law and which differs greatly from other historiographies of crime. It is then confirmed that the historicity of crime, besides the notion of historical time through which the past of criminal law has been interpreted, have been conditioned by determinisms and reductions that have been combined very well with the dogmatics of criminal law.
\end{abstract}

Keywords: Crime's historicity, criminal law's handbooks, evolution, law's pedagogy.

\section{Introducción}

Este artículo examina la producción bibliográfica del derecho penal colombiano desde la última década del siglo XIX y durante todo el siglo XX relacionada con la historia del delito. Este análisis focaliza algunos textos de enseñanza del derecho y denomina a esta literatura jurídica como manualística ${ }^{1}$ del derecho penal. Esta literatura está conformada por los manuales de derecho penal y por otros géneros de escritura como los cursos introductorios, los compendios y los esquemas de autores locales. Además, se han consultado las notas de los profesores de derecho penal y algunas tesis impresas publicadas entre la década de 1890 y los años treinta del siglo XX en Colombia. La principal característica historiográfica de esta literatura jurídica es que ha

Notas de autor 
concebido la historia del delito en una perspectiva reduccionista, anecdótica y descriptiva. La anterior visión de la historia ha propiciado la estrechez interpretativa de la historicidad del delito, toda vez que el análisis reflexivo de los procesos y de las relaciones sociales, así como el encuadramiento histórico del crimen, no han sido dominantes entre los abogados colombianos como sí lo han sido en otras áreas del conocimiento distintas al derecho. Entonces, se plantean problemas teóricos, pedagógicos y narrativos que supeditan la historicidad del delito a los dogmas jurídicos que pueden ser definidos como abistóricos.

Como se podrá observar, la historia del delito que conciben los abogados a través de la manualística del derecho penal no relaciona los procesos políticos, económicos, sociales y culturales con el contexto en que se producen los fenómenos delictivos ${ }^{2}$; entonces, sus formulaciones teóricas explicativas del crimen se ciñen estrictamente a las instituciones penales que han sido enseñadas mediante un ejercicio memorístico ${ }^{3}$. Esta historiografía dista de la historia elaborada por los historiadores - o en general, por los científicos sociales e incluso, criminólogos-, para quienes el delito no puede ser analizado históricamente sin tener en cuenta su complejidad contextual ${ }^{4}$.

Ahora bien, esta visión específica de entender la historia del delito en Colombia provino de ámbitos distintos, los que se complementaron en la formulación de una idea de historicidad en la cual se basa el derecho penal. El primer determinante es teórico y pertenece al mundo del derecho; de modo particular, está relacionado con la idea según la cual el fundamento del derecho yace en el Estado. Esta situación fue propicia para la aceptación del credo que sigue vigente y que afirma que la única faceta de lo jurídico a tener en cuenta en los estudios científicos del derecho es la norma positiva. Un segundo nivel determinante es el pedagógico; evidentemente, durante los siglos XIX y XX dominó en las aulas un modelo de enseñanza jurídica que se sustentó en la memorización, en los juicios acríticos y en la exposición magistral; al parecer, este enfoque de la pedagogía del derecho penal persiste aún hoy ${ }^{5}$. El último factor que alteró la idea de la historia del delito en la manualística del derecho penal fue ideológico, pues consistió en la amplia aceptación e incorporación de la teoría evolucionista en el derecho penal colombiano. Esta adaptación de un modelo explicativo que provino de la biología reforzó una historia lineal y en este acomodo, ocurrió la confusión entre los conceptos de evolución y progreso civilizatorio propios del positivismo filosófico y científico. Así pues, una de las consecuencias de esta elección ideológica en la manualística del derecho penal ha sido que el delito sea explicado históricamente a partir de una relación mecánica del cambio social ${ }^{6}$.

De acuerdo a estos planteamientos, este artículo se compone de cuatro apartados. Un primer aspecto que se analiza es la incidencia de los fenómenos del formalismo jurídico y del legalismo como orientadores de la historicidad del delito. En este primer punto, se introduce la relación de la enseñanza tradicional del derecho y el mundo intelectual del libro como circunstancias que condicionaron la historiografía jurídica. Un segundo aspecto profundiza en el concepto de la evolución aplicado al derecho y en cómo dicho concepto sesgó la noción del tiempo histórico. En tercer lugar, se habla de las características y la tipología de los manuales; finalmente, el artículo enseña cómo se concibió una historicidad del delito determinista y reduccionista en la manualística del derecho penal.

\section{El formalismo y la pedagogía del derecho}

Este apartado introduce la discusión del formalismo y del legalismo, conceptos a través de los cuales se describe una creencia que encasilla al derecho en aspectos puramente formales. Además, se hace un recuento del modelo tradicional de la pedagogía del derecho, así como de su cultura libresca, para argumentar que estos aspectos favorecieron la concepción reduccionista de la historia del delito en Colombia, pues estos elementos dieron prioridad a la interpretación abstracta de los hechos delictivos en perspectiva histórica.

Inicialmente, la importancia del formalismo tiene sentido si los abogados y la sociedad en general piensan que el único objeto de la ciencia del derecho es la ley positiva. Esa opinión formó parte de la cultura jurídica 
occidental - en especial, en el continente europeo- y perduró desde el siglo XIX hasta la primera mitad del siglo XX. En la actualidad, algunos autores encuadran tanto el formalismo como el legalismo siguiendo algunas rutas de aproximación y diferenciación con el positivismo. Este juego conceptual es clave para comprender el apego de los abogados por una manera de escribir la historia del delito en Colombia.

En este texto se entiende que el formalismo jurídico es, de acuerdo con lo expresado por DUNCAN KENNEDY, un "concepto controvertido" que surgió asumiendo puntos de vista críticos de la historia del derecho, la sociología jurídica, el derecho comparado, la filosofía del derecho, los estudios culturales del derecho y los campos interdisciplinares del derecho para dar sentido a la idea que refleja la coherencia en un sistema jurídico. De modo que el formalismo ha servido de insumo para discutir, inicialmente, el "grado de insistencia en el cumplimiento de las formalidades" legales ${ }^{7}$. También indica los usos de una técnica de interpretación jurídica que se basa en el significado de las normas y, en este orden de ideas, se hace necesaria para reconocer la coherencia en el derecho. Por lo anterior, una de las mayores críticas recae en considerar que - admitiendo un abuso metodológico que el formalismo hace de la deducción- los hechos sociales son relegados por la abstracción jurídica. Sobre el particular, DIEGO EDUARDO LÓPEZ-MEDINA subraya que desde el punto de vista del formalismo, el derecho es "básicamente una actividad destinada a examinar textos preexistentes (por oposición a realidades, intereses o necesidades), que la interpretación del derecho produce generalmente resultados definitivos y correctos, y que en el sistema jurídico no hay vacíos porque hay formas cognitivamente razonables de llenarlos" 8 .

Dentro de esta lógica, el formalismo se puede pensar como un fenómeno jurídico complejo que reúne algunos aspectos con los que se ejerce la crítica a un sistema jurídico. Pero sobre aquel también pueden recaer serios cuestionamientos: en primer lugar, el formalismo es "necesario y suficiente para llenar ciertas formas consistentes en el cumplimiento exacto de prácticas o ritos conforme a un modelo determinado" 9 ; es decir, este es el tipo de formalismo que se encuentra en un ordenamiento jurídico. En segundo lugar, desde la óptica de la justicia, el formalismo se cumple cuando una actuación se ciñe a un esquema preestablecido, por tanto, se trata de un acto justo. En este punto es definitivo considerar que tal esquema es fijado por la ley positiva, además, el formalismo asume un "único método interpretativo" y un único significado posible de los enunciados normativos. Finalmente, otro aspecto del formalismo jurídico, perteneciente a la actividad científica del derecho, es aquel que consiste en el desapego a los "progresos y las investigaciones extrajurídicas" 10 . Así las cosas, la síntesis del formalismo que se puede aplicar para los propósitos aquí indicados es su capacidad para reducir las cualidades de la realidad a simples asuntos abstractos.

De otra parte, el legalismo es la distancia existente entre la jurisprudencia y la teoría social. De hecho, la separación entre el derecho y la sociedad es de tal magnitud que aún impera un credo entre los abogados: "la posibilidad de considerar el derecho como un modelo conceptual enteramente distinto de todos los valores e instituciones políticas, morales y sociales simplemente se da por sentada" ${ }^{11}$. Sobre este particular, JUDITH N. SHKLAR añade que la condición ahistórica de la relación entre el derecho y la realidad social radica en que el legalismo consiste en "una teoría que distingue el derecho de la moral, en función de las presiones ejercidas para lograr la conformidad y, luego divide estas presiones en oficiales y privadas", por lo que resulta ser "históricamente demasiado selectiva" 12 .

En el caso colombiano, el formalismo no necesariamente aparece ligado en un primer momento al positivismo, pues en el contexto local surge asociado más a lo que LÓPEZ-MEDINA conoce con el nombre de clasicismo, o formalismo clásico ${ }^{13}$. Para este autor, durante el siglo XIX se fraguó una combinación de ideas de autores franceses y alemanes, que cuando menos vino a justificar el apego al formalismo. Otra opinión entiende el clasicismo como una serie de prácticas tradicionales en la cultura jurídica colombiana, que contribuyó al estancamiento del desarrollo científico del derecho en el país. En ese sentido, ISABEL GOYES-MORENO sostiene que entre 1886 y 1930, aunque se pusieron en marcha distintos métodos en la interpretación y concepción de la ley y del derecho, primó en la enseñanza del derecho y en el quehacer 
del abogado el método exegético, a la vez que se mantuvo una formación escolástica de los estudiantes de derecho que respondía a los intereses de un Estado seudoconfesional. En el campo de la enseñanza jurídica, GOYES-MORENO afirma: “Así las cosas, enseñar derecho era como enseñar religión, se trataba de verdades irrefutables, completas, inmodificables, verdaderas, donde las deficiencias del aplicador jurídico debían subsanarse con el mismo texto legal o con la identificación del querer del legislador" 14 .

Al margen de los usos del formalismo y del legalismo, la educación legal que recibieron los abogados durante los dos últimos siglos ayudó en la elaboración del tipo de historia del delito en Colombia ${ }^{15}$. Todo indica que en las aulas de derecho desde finales del siglo XIX fue corriente el empleo de un método pedagógico que resaltó el conocimiento memorístico. En efecto, los abogados profesores de derecho, generalmente catedráticos, se encargaron de acentuar estrategias pedagógicas que incrementaban la memorización: la exposición magistral ${ }^{16}$ y el dictado, cuyo origen se remonta a la escolástica medieval ${ }^{17}$. Asombrosamente, la imagen que brindan las investigaciones contemporáneas del método de enseñanza legal en Colombia varía poco del contexto universitario de las facultades de derecho del siglo XIX: "La minuciosidad de su contenido, la verticalidad de su jerarquía, la ortodoxia de su pensamiento, correspondían a un modelo de currículo teórico confesional, cuya pretensión era modelar el pensamiento y el futuro comportamiento de sus egresados" 18 . De manera que es recurrente darle un sentido negativo al método tradicional, que se agudiza mientras la tradición pedagógica tiende a fomentar la orientación doctrinaria en el derecho ${ }^{19}$.

Por consiguiente, las opiniones negativas recaen más en el proceso pedagógico que se apoya en la formación de conocimiento memorístico, dada su inutilidad para fomentar el pensamiento crítico y reflexivo ${ }^{20}$. Esta enseñanza jurídica se valió del libro de texto para apuntalar el ideal memorístico en el conocimiento, pues facilitó la labor de docentes y estudiantes; total: el manual de derecho penal se constituyó un sucedáneo de las clases tanto para los estudiantes como para los mismos profesores ${ }^{21}$. Una de las respuestas al porqué resulta tan incómodo el método tradicional de enseñanza del derecho se resume en lo complejo que resulta hoy entender el mundo del derecho con los métodos del pasado, ya que "los métodos docentes tradicionales podían resultar hasta cierto punto aceptables en una sociedad subdesarrollada con un Derecho fundamentalmente tradicional, pero no lo son en una sociedad avanzada, en la que el volumen y complejidad del Derecho han aumentado de manera espectacular" 22 .

Se debe añadir que este tipo de análisis que se centra en el libro de enseñanza del derecho penal debe precaver de cuán significativa fue la cultura libresca en la formación de los abogados colombianos. Una idea general para desarrollar este punto es la que sostiene que los libros se convierten en un bien no solamente simbólico sino también material, mediante el cual se hacen distinciones culturales que tienen correlación con el rendimiento escolar y con el ascenso social. PIERRE BOURDIEU piensa que el acceso a los libros es uno de los tres tipos de capital cultural o estado objetivado, y se compone además de los libros por cuadros, diccionarios, instrumentos o maquinarias que definen la formación en una profesión ${ }^{23}$. Interesa ver que la posesión de los manuales de derecho penal abre la posibilidad de transmitir, en mayor o menor grado, una cultura jurídica por la vía material, por lo que el incremento del capital cultural en su estado objetivado llevaría al aumento del capital (medios de producción) y al afianzamiento de una clase dominante ${ }^{24}$.

En otras palabras, la posesión de libros está relacionada con la acumulación de capital económico. En el caso colombiano, el modelo explicativo de Bourdieu puede compaginarse muy bien con los datos suministrados por los pocos historiadores que analizan la historia intelectual en el campo del derecho. Antes de la segunda mitad del siglo XIX, el manual de derecho es casi inexistente, pero empieza a sustituir al catecismo civil. De otra parte, circunstancias como la tardía introducción de la imprenta en Colombia y el alto costo de los libros van perfilando un público selecto que prefirió el manual, debido a la simplicidad mecánica de aprender repetidamente datos. ANA MARÍA OTERO lo explica de este modo: "En consecuencia, la redacción y las condiciones materiales de los textos determinaron no solo el público al que iban dirigidos sino la forma 
cómo debían ser leídos. Su formato denota la idea que existía un conjunto de verdades que los lectores debían aprender de memoria" 25 .

En suma, los aspectos teóricos mediante los cuales se entendió una faceta del derecho - es decir, el formalismo y el legalismo- surtieron las herramientas cognitivas para formar un esquema conceptual mediante el cual fue interpretada la historia del delito en Colombia. A ello se suma la pobreza del mundo libresco que vivió el derecho colombiano finalizando el siglo XIX y a inicios del siglo XX, que conformó un marco reducido del análisis que se centró en ejercicios repetitivos consonantes con un modelo de enseñanza jurídica tradicional.

\section{La evolución como categoría historiográfica en la historia del delito}

Este apartado muestra cómo el concepto de evolución condicionó la comprensión del tiempo histórico y le dio sentido a la noción de la historia del delito en Colombia. Además, el uso habitual - mecánico e irreflexivode este concepto en la manualística del derecho penal colombiano condujo a que la historia del delito fuera estudiada en un marco de pensamiento determinista. Como todo determinismo, la creencia incontrovertible de que la evolución era un punto capital en la historia del delito derivó en reduccionismos y la evolución dejó de ser un concepto más para convertirse en una categoría de análisis central en la historiografía jurídica. Este reduccionismo estaba relacionado, desde luego, con una convicción según la cual el tiempo presente merecía mayor interés investigativo que el pasado remoto ${ }^{26}$, puesto que tendió a encasillar fenómenos pretéritos y actuales como si fueran una misma cosa ${ }^{27}$. Esta tendencia analítica dio como resultado un desprecio de los autores de textos de enseñanza del derecho penal por historiar reflexivamente temas como el delito. Pese a sus limitaciones, esta forma de comprender la historia sirvió a los abogados para contrastar los defectos de la sociedad con sus propias aspiraciones civilizatorias ${ }^{28}$.

Al hablar de la evolución se hace referencia a un proceso irreversible que consiste en pequeños cambios que sufren los organismos a través del tiempo. El principal elemento de la evolución es la selección natural, lo que significa que la vida prospera en un medio ambiente adecuado y, por tanto, los organismos más exitosos son los que mejor se adaptan a su medio y pueden reproducirse en mayor número ${ }^{29}$. El prestigio que logró la teoría evolutiva en América Latina hasta la primera mitad del siglo XX resultó en dos enfoques que sirvieron a los penalistas y a los criminólogos para explicar el delito. El empleo de estos enfoques deterministas, el determinismo biológico y el darwinismo social, provocó una ideologización en las ciencias sociales, que es lo mismo que someter cualquier fenómeno social a las explicaciones biológicas ${ }^{30}$. Entonces, uno de los autores que más orientaron la perspectiva evolutiva entre los científicos sociales y los abogados fue Herbert Spencer 31 , quien interpretaba la evolución como la serie de transformaciones que sufren los organismos biológicos cuando cambian su estructura ${ }^{32}$. A su vez, en la dinámica evolutiva se cumplen leyes universales, como la que afirma que la vida evoluciona de los organismos más simples a los más complejos, por lo que fue sencillo suponer que las sociedades pasaron de organizaciones básicas — como las jefaturas - a formas más avanzadas — como los estados teocráticos y, finalmente, las organizaciones estatales- ${ }^{33}$.

En este complejo analítico, la confusión entre los conceptos de evolución y progreso fue definitiva, pues este último hacía alusión al éxito aparente de la sociedad industrializada de finales de siglo XIX e inicios del siglo XX y que se manifestó en dos circunstancias: la más básica fue pensar el progreso como la acumulación material que ocurrió con el capitalismo industrial; la segunda circunstancia hizo alusión a la capacidad de la inventiva humana. SPENCER manifestó en un primer momento que: “[...] el progreso social consiste en la producción mayor y más variada de los objetos necesarios para satisfacción de nuestras necesidades, en la creciente seguridad personal y de la propiedad y en la amplitud concedida a la libertad de acción" 34 . Por 
tanto, el derecho penal moderno vino a convertirse en un producto del progreso, y la consecuencia de todas estas ideas asociadas a la evolución se resumió en un escaso interés por la reflexión histórica.

Esa perspectiva evolutiva, además de apoyarse en las referencias a SPENCER, también acudió a las ideas de JEAN-BAPTISTE LAMARCK y CHARLES DARWIN. En el caso colombiano, SPENCER sirvió como un referente de autoridad intelectual, pues fue citado frecuentemente por los abogados penalistas en sus tesis y en los cursos que dictaron los profesores de derecho penal, lo que demuestra cómo acogieron el esquema evolutivo de interpretación histórica no solo del delito, sino también de la pena y del derecho penal. Los autores en mención escribieron sus tesis a finales del siglo XIX hasta la década de 1930, cuando la divulgación del positivismo penal estaba en pleno auge en Colombia. A finales del siglo XIX, ARTURO QUIJANO emprendió un ejercicio de síntesis histórica del derecho penal colombiano que incorporó una periodización de grandes temporalidades. La importancia del libro de QUIJANO radica en que quizás sea la primera tesis publicada en Colombia que abordó la historia del derecho penal como tema central. El texto, aunque tiene la virtud de la originalidad, tiende a encasillar los procesos sociales en temporalidades deterministas, ya que son divisiones del tiempo histórico cerradas y arbitrarias. En este sentido, QUIJANO supuso que los pueblos prehispánicos habían vivido la mayor parte de su vida social en una etapa oscura e indeterminada, mediada por la idolatría, el canibalismo, el despotismo y la hechicería, hasta cuando conocieron la civilización jurídica de la cristiandad ${ }^{35}$.

Entonces, no es de extrañar que el impacto de la teoría evolutiva fuese visto como un hecho intelectual de primer orden por la Sociedad Jurídica, organización adscrita a la Universidad Nacional de Colombia y conformada principalmente por estudiantes. Con ocasión de su discurso inaugural en 1916, su presidente reiteró que el evolucionismo "[...] asentó como base primera del sistema la tesis de que el desarrollo jurídico principia lo mismo en todos los hombres en estado primitivo y continúa de modo uniforme, inalterable, igual para todas las sociedades y para todas las razas" ${ }^{36}$. En la década siguiente, las explicaciones históricas del delito continuaban sometidas a los postulados de la evolución ${ }^{37}$. Puntualmente, el eje de atención de la comprensión histórica del crimen se limitaba a focalizarlo como un rasgo del primitivismo humano, ya que el crimen — según la ideología evolutiva - se caracterizó como una reacción instintiva heredada de los animales. Así, el abogado ERNESTO GONZÁLEZ-PIEDRAHITA reafirmó la idea de que no solo el derecho penal estaba sujeto a la evolución; el crimen también era un hecho evolutivo: "Los hechos delictuosos, como manifestaciones de la vida social, siguen el movimiento incesante de su evolución, [...] la animosidad impulsiva es hoy considerada como una reminiscencia de los instintos del hombre primitivo, porque el ambiente civilizado dulcifica el carácter y hace cada vez más rara la explosión de pasiones feroces" ${ }^{38}$.

Las ideas de la evolución quedaron registradas no solo en los trabajos de los tesistas, sino en los de prestigiosos profesores de la Universidad Nacional como RAFAEL ESCALLÓN y JORGE ELIÉCER GAITÁN, quienes enfatizaron la teoría evolutiva como la lógica que daba explicación al crimen. GAITÁN, convertido por aquel entonces en una figura pública, expuso su opinión respecto al origen histórico del delito: "Podría decirse que el fenómeno delictuoso encuentre su génesis en un asiento biológico, lo cual nos lleva a afirmar que tiene su origen en una razón universal, en el principio de la evolución transformadora del mundo que nos rodea" 39 . Por su parte, ESCALLÓN enseñó el lugar que ocupaba la historia en el esquema interpretativo de la teoría evolutiva, así:

Las instituciones jurídicas viven en perpetua evolución aunque no la percibamos. Para llegar a esta consideración tenemos que aplicar la reflexión y valernos, de otros elementos de instrucción como la historia, que nos dicen del movimiento seguido por las instituciones a través de los tiempos. Es necesario estudiar bien las cosas, para llegar a saber que tal vez han mediado siglos entre etapa y etapa de la evolución de una institución determinada 40 .

También en la década de 1930, la tesis del abogado PEDRO CARREÑO señaló como idea basal de la historia del derecho penal el que "se puede dividir la evolución de la pena lo mismo que la evolución de la función penal. A saber: venganza privada, Ley del Talión, sistema de las composiciones, venganza divina, 
venganza pública y fase científica” ${ }^{41}$. CASTOR ANTONIO CEPEDA concibió el tiempo histórico relacionado con la historia del delito en grandes períodos inmodificables, que iban desde el derecho primitivo, el derecho teológico, el iluminismo ilustrado, hasta llegar al derecho científico: "Todo proceso marcha lentamente por etapas, por períodos, conforme a los períodos de la cultura y civilización de los pueblos" ${ }^{42}$.

Distinto a generar unas pautas interpretativas de la historia del delito, el evolucionismo y el apego a la categoría de la evolución como senda historiográfica les permitieron a los abogados penalistas —en especial a los que produjeron material bibliográfico hasta la primera mitad del siglo XX - ajustar las contradicciones de la sociedad colombiana (como el subdesarrollo económico y el anhelo de alcanzar la industrialización) con los adelantos de la sociedad capitalista en campos tan diversos como la ciencia, las artes o la economía ${ }^{43}$ - Así, el utillaje teórico del evolucionismo, que gozó de gran prestigio en los círculos científicos del mundo occidental, les daba a los hombres de ciencia locales la opción de encuadrar fenómenos como el crimen en unas expectativas de civilización. En este sentido, el derecho penal era concebido como una gran presa que reducía la fuerza de las aguas del primitivismo ${ }^{44}$.

A la vez que el evolucionismo aportó a los intelectuales del derecho penal colombiano un esquema interpretativo del delito, que lo encasilló como un epifenómeno de las anomalías biológicas, lo supo dotar de una estructura que organizó el tiempo histórico en el que se desarrolló la historicidad del crimen. Esta clasificación cronológica estaba sujeta a grandes etapas que emulaban las fases biologicistas del desarrollo de los seres vivos. Enfáticamente, la historia permaneció como un instrumento subordinado de la biología y, por tanto, el sentido historicista de la historia del crimen quedó inmerso en este reduccionismo. También el manejo frecuente de la noción de la evolución en la escritura histórica del derecho penal estuvo acompañada de un canon escritural, preeminentemente descriptivo, en el que la acumulación de datos se sobrepuso a la explicación de los procesos históricos. De otra parte, la manualística del derecho penal divulgó en Colombia los desarrollos de la Ilustración, que fue considerada por esta tendencia literaria como el gran triunfo evolutivo de la civilización jurídica occidental sobre la barbarie.

\section{La tipología de la manualística del derecho penal}

Este apartado profundiza el estudio de los manuales de derecho penal que por sus funciones pedagógicas se convierten en los libros de preferencia de los estudiantes de derecho. En la actualidad, el impacto de estos libros es considerable, pues el tamaño de su mercado en Colombia es proporcional al número de estudiantes de derecho ${ }^{45}$. En esta investigación, el análisis del manual de derecho penal es nuclear, ya que el manual incentiva en los estudiantes la creencia de la supremacía de la ley codificada respecto a otras facetas jurídicas de la sociedad, de manera que este sesgo interpretativo arrincona el estudio histórico de la ley a un lugar subordinado. También la importancia analítica de esta clase de libros yace en que pueden servir como fuente para comprender cómo los abogados penalistas construyeron el sentido de historicidad del delito en Colombia.

Algunos manuales afirman que el iluminismo o el humanismo lograron modificar el derecho penal premoderno en varios aspectos. Autores como GAETANO FILANGIERI, CESARE BECCARIA o JEREMY BENTHAM son mencionados de manera ampulosa para consolidar unas pautas de entendimiento en la transformación iluminista del derecho penal ${ }^{46}$. Así, las nociones acerca del derecho moderno destacan el sentido que procura la objetividad en la responsabilidad penal, la mesura de las penas y su "dulcificación" en un telón de fondo que asienta la legalidad como principio fundante.

Además, se trata de libros que ordenan los temas de acuerdo a jerarquías conceptuales y normativas; por demás, los manuales son esquemáticos y abrevian las teorías del delito para su comprensión sintética en las aulas, ya que describen el ámbito de validez de la ley penal en un contexto espaciotemporal. Uno de los aportes de esta investigación es que, dado que se organizan como compendios y que en su mayoría acopian argumentos 
jurídicos de autorreferencia, su examen constituye el trabajo de base para proyectar una historia conceptual del delito. Dicho de otro modo, el concepto del delito puede ser visto como objeto de transformación histórica tanto en el contenido de su significado como en los usos políticos, sociales y jurídicos de esos significados aplicados en contextos históricos específicos.

Otra de las ideas que surgen en este análisis es la que indica que los manuales tienden a fomentar el conocimiento memorístico del derecho. Ya JOSÉ VICENTE CONCHA había definido a finales de siglo XIX las funciones del manual como un compendio de las ideas de autores clásicos en notas breves que los estudiantes de derecho podían emplear a manera de resumen, "como un auxiliar de la memoria de los alumnos" 47 , para así medir sus avances intelectuales al momento de enfrentar una exposición oral ${ }^{48}$. Tal orientación memorística de la enseñanza del derecho tuvo más repercusión durante la Regeneración [1878-1898] y se prolongó hasta el siglo XX; este hecho fue explicado por el abogado y sociólogo EDUARDO UMANALUNA, quien indicó cómo desde 1867 hasta 1935:

tanto los docentes como los educandos se encontraban limitados en el desarrollo de los cursos. Situación que se haría totalmente nugatoria para cualquier intento de investigación (objetiva e imparcial). En la facultad dominaba la metafísica en la docencia. En otras palabras, retrocedía gravemente porque mientras se producían los avances de la ciencia, la Facultad se encontraba en plena aparición del Humanismo Social. (...) El memorismo, la automática repetición de conceptos, la privación de todo tipo de análisis eran los amos del Claustro 49

A este panorama colombiano del derecho finisecular, dominado por una mixtura entre el catolicismo hispano y un positivismo temprano, se añaden tres elementos que reanimaron el uso de la memoria en el conocimiento jurídico. El primero es señalado por el filósofo RUBÉN JARAMILLO-VÉLEZ como un contexto filosófico de simulación, que consistió en la propagación del latín y del clasicismo entre los abogados, lo que modeló una personalidad intelectual impermeable a la fundamentación filosófica ${ }^{50}$. El segundo fue la carencia de instrumentos didácticos en la enseñanza del derecho concernientes a la discusión teórica en la segunda mitad del siglo XIX, pues "no existía en Colombia, entre 1850 y 1900, una cultura de publicaciones de tratados de derecho" ${ }^{51}$. El tercer elemento consistió en el civilismo, que la historiografía política entiende como la preponderancia de los abogados en los asuntos públicos o de Estado ${ }^{52}$. Escindidos entre legos y doctos, los abogados colombianos dieron más valor al saber empírico que al conocimiento teórico ${ }^{53}$.

Ahora bien, los contenidos históricos responden a una teleología política en la cual la historia del derecho es el correlato de la historia del Estado. Esta misma interpretación del pasado cobija tanto a la historia mundial del derecho penal como a la historia jurídico-penal colombiana. No obstante, la manera de prescindir de la explicación histórica subyace en el apremio de los manuales por justificar el desarrollo del derecho penal con el éxito de la filosofía jurídica liberal, lo que requiere tanto más de una demostración empírica; pero lo que termina ocurriendo, en el peor de los casos, es una suerte de convencimiento a través de la repetición de esta idea ${ }^{54}$, que se ampara para ello en la autoridad intelectual de los manuales más reconocidos o simplemente "clásicos".

Por último, estos libros se pueden clasificar en dos tipologías. La primera corresponde a los manuales que interpretan la ley penal sustantiva; por tanto, obvian la historia como instrumento de conocimiento y su publicación está inspirada en la vigencia de un código penal. Son sus rasgos más significativos el comentario del autor, la opinión personal, la cita extensa de la ley, la presentación esquemática de los tipos penales y la referencia al significado de los verbos rectores 55 . La segunda categoría de libros se propone brindar un breviario de la teoría general del derecho penal y resulta de un cúmulo de intereses que lleva a justificar un nuevo ideario o "escuela". De hecho, los manuales más recientes enumeran tantas escuelas como teorías jurídicas, así: la escuela clásica, la escuela positiva, la Terza Scuola, la crítica al positivismo, el finalismo y el funcionalismo. A pesar de sus discrepancias, los manuales confluyen en la afirmación según la cual, pese a que las distintas corrientes de pensamiento o escuelas han tenido variaciones en su objeto de estudio y se concluye que "el objeto de la ciencia penal ha sido en esencia siempre el mismo —el derecho positivo" — 56 . 
Podría decirse que la segunda tipología de manuales de derecho penal incorpora más elementos de juicio acerca de la historia del delito. No obstante, el semblante doctrinal es una constante que va a la par de una reafirmación de la ley positiva 57 . En lugar de fomentar el racionamiento crítico y la problematización del conocimiento, los manuales manifiestan una serie de elementos persuasivos con el fin de lograr un acuerdo epistemológico en torno a la historia del delito y la resumen como la simple violación de la ley. Lo anterior produce que los contenidos jurídicos desarrollados a través de los años se acomoden al carácter de la ley y no que respondan a los hechos sociales. Los matices de tal fenómeno planteados por los manuales evidencian una discrepancia en las formas de pensamiento de los "maestros" (los teóricos del delito) que dificulta la elaboración de una noción unificada del delito, por lo que emerge como último recurso para salir del atolladero enarbolar repetidas veces la definición del delito como la simple violación legal ${ }^{58}$. En este orden ideas, se reitera el fundamento del derecho penal en los mismos términos que del delito, pues "el derecho penal es un ordenamiento dogmático; su objeto es la norma, entendida como hecho cierto, como regla imperativa de comportamiento, que deben acatar todos los coasociados y que emana de los poderes públicos del Estado" 59 .

\section{La manualística del derecho penal y la idea de la historia del delito}

La historicidad del derecho penal en la manualística, y por extensión la historicidad del delito, inician en un pasado remoto e indeterminado y que es presentado como un "estado primitivo" de las sociedades en las cuales la infracción se resolvía a través de la venganza ${ }^{60}$. Otro tanto ocurre al intentar entender las formas delictivas de las sociedades prehispánicas ${ }^{61}$. A este primer estadio le sucede el período civilizatorio, con referencias a los egipcios, sumerios o hebreos, para quienes las formas del delito estaban enmarcadas por la teología y por la ley del talión. Enseguida se llega a la historia grecorromana y de allí al período medieval "oscurantista"; finalmente se arriba a la modernidad, que despunta el iluminismo y la cientificidad del siglo XIX ${ }^{62}$.

El estilo esquemático y disperso de los manuales redunda en un diseño ligero de los argumentos y de los conceptos históricos, que son tomados de los exponentes de las escuelas penales, generalmente bajo el título de "antecedentes". Luego, en algunos casos, se presentan dos o tres líneas que caracterizan esas corrientes del pensamiento jurídico penal. A renglón seguido, los manualistas presentan su juicio sobre los argumentos históricos bajo la denominación de "evaluación”, "conclusión”, "nuestro criterio es”, "nuestra opinión”, “crítica” o "valoración".

En Colombia, la publicación de la manualística del derecho penal se consolida a mediados del siglo XX, como lo sostiene BERNARDO GAITÁN-MAHECHA, con los manuales de LUIS CARLOS PÉREZ, AGUSTÍN GÓMEZ-PRADA y CARLOS LOZANO Y LOZANO ${ }^{63}$; sin embargo, hay libros previos a esta fase de afianzamiento literario: a finales del siglo XIX se publicó el destacado Tratado de derecho penal del expresidente JOSÉ VICENTE CONCHA ${ }^{64}$. Un segundo momento de vida editorial manualística aparece ligado a la expedición del Código Penal de 1980, y el tercer momento tiene como eje las reflexiones que suscita el Código Penal del año $2000^{65}$.

Como ejemplo destacado de la primera etapa en 1953, LUIS CARLOS PÉREZ publicó el libro Derecho penal colombiano, cuyos objetivos eran exponer y analizar la doctrina penal "en su significación universal". Según PÉREZ, la dependencia intelectual de autores extranjeros ha reducido la capacidad creativa de los penalistas colombianos, a tal punto que sostuvo que el derecho colombiano ha sido construido con ideas foráneas que se imbrican en el ordenamiento penal: "La escasez de especialistas de derecho penal puede explicarse parcialmente por el desarraigo de nuestras leyes, defecto crónico de nuestro pasado" 66 . De este modo, PÉREZ justificaba la renovación de las ideas penales; aunque en su propuesta innovadora PÉREZ 
incluye la historia, lo hace con una perspectiva instrumental que le sirve como banco de prueba para sostener un artificio de pesquisa en los errores y bondades del Código Penal colombiano de $1936^{67}$.

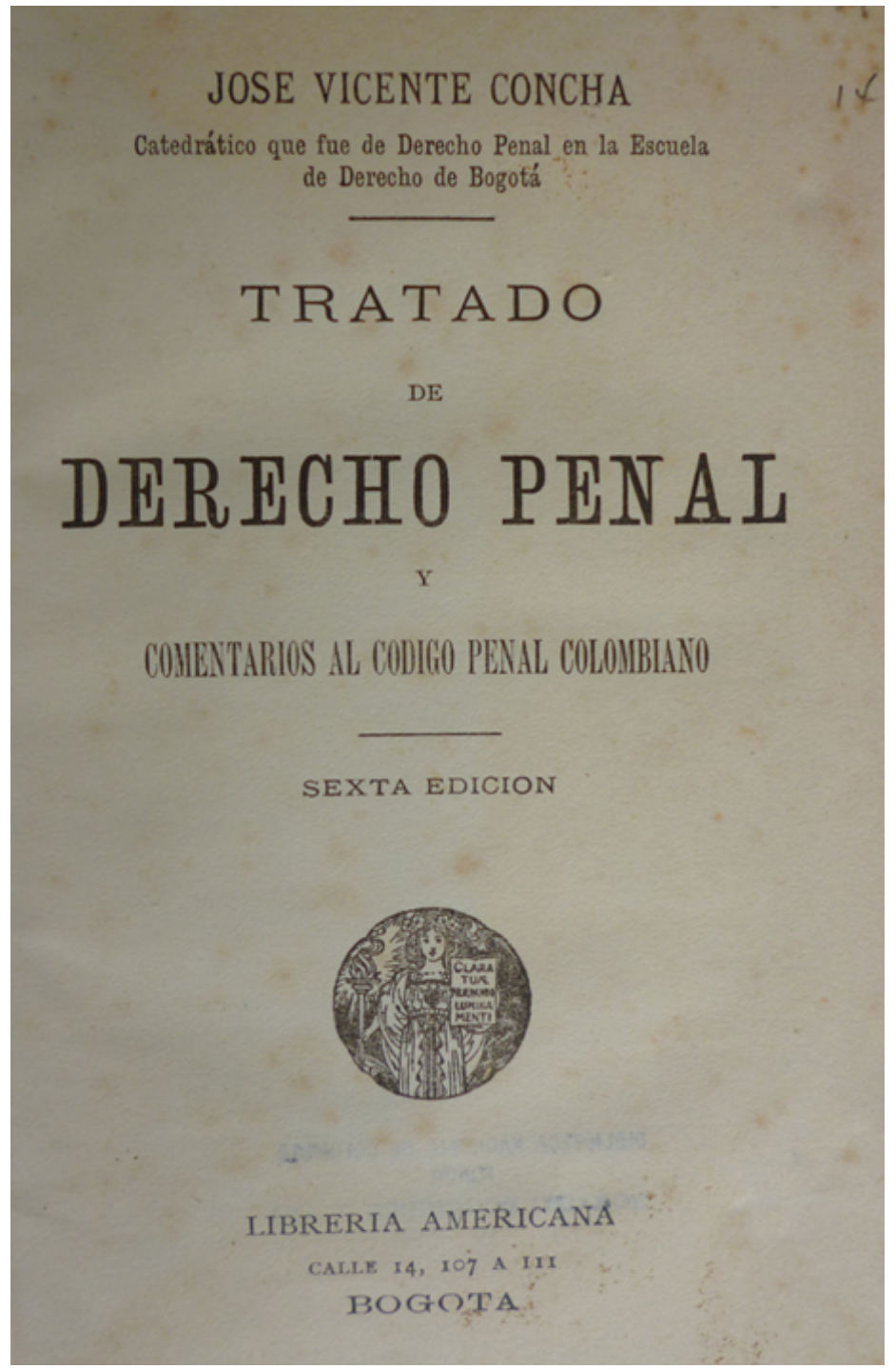

Portada del libro de JOSÉ VICENTE CONCHA, Tratado de derecho penal (6 ${ }^{\mathrm{a}}$ ed., Librería Americana, Bogotá, 1896). 


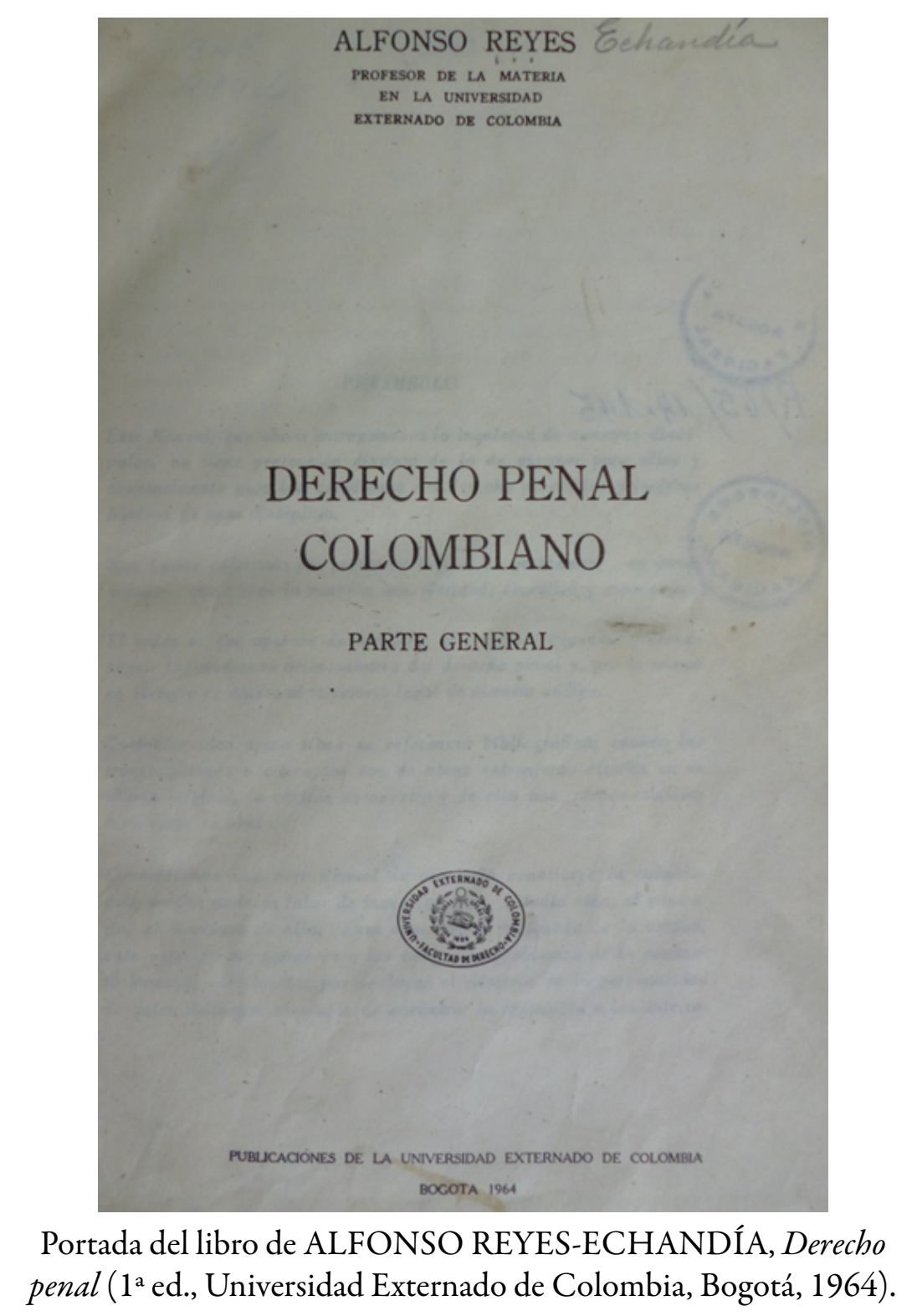

PÉREZ también escribió el libro Derecho penal. Partes general y especial a la luz de la implementación del Código Penal de $1980{ }^{68}$. La escritura de PÉREZ hace una crítica al positivismo del Código de 1936, al que califica de "liviano y expedito", y que busca replantear la forma de entender el pensamiento jurídico en consonancia con los cambios que trajo el nuevo código. Este manual, luego de exponer en varias páginas un recorrido histórico desde el pasado remoto, subraya como conclusión que el delito llega al humanismo cuando es por fin comprendido científicamente ${ }^{69}$.

Quizás uno de los manuales de mayor prestigio sea el libro Derecho penal, de Alfonso REYESECHANDÍA, pues goza de varias ediciones y reimpresiones. La descripción que hace el autor de la historia del delito - en forma muy implícita - lo lleva a conjeturar que en el pasado las sociedades resolvían el delito en un halo "oscurantista" de violencia. Según REYES-ECHANDÍA, el delito era igual al pecado ya que tal definición se configuraba en las disposiciones teológicas ${ }^{70}$. La historia jurídica colombiana es presentada en Derecho penal bajo el título de "noticia histórica", en la que se piensa que la codificación penal del país es una etapa más en un largo proceso que viene desde los romanos. Esta descripción de la violencia y su mitigación como matriz para la lectura de la historia del derecho penal es compartida por ÁLVARO ORLANDO PÉREZ-PINZÓN, quien afirmó que la historia penal consiste en una sucesión de crueles sistemas de castigo. 
Entre los antiguos mesopotámicos, egipcios y chinos, la pena tenía como propósito acrecentar el miedo en la población, y fueron los romanos quienes suavizaron las penas que parecen tornarse más severas con los germanos; por su parte, los hitos de la modernidad que ponen límite a la violencia en esta perspectiva son la Revolución Francesa y el cientificismo del siglo XIX ${ }^{71}$.

Uno de los manuales publicados en 1983 analiza el Código Penal de esa década (Decreto 100 del 23 de enero de 1980), y señala que el análisis del código debe hacerse sobre las bases de las fuentes legítimas para que los alumnos "[...] juzguen reflexivamente si en verdad la nueva ley tiene nuevas orientaciones de la ciencia, diferentes a las que puedan encontrar en los tratados ordinarios de consulta [...]” 72 . En este manual, dedicado a una comprensión de lectura del Código Penal de 1980 en 450 páginas, solamente integra un párrafo de la historia del crimen. Otro ejemplo de manual de este primer tipo es anunciado como "una obra didáctica de alta calidad y gran enjundia” y en él se hace un cotejo de los tipos penales del Código colombiano de 1980, con arreglo al Código Penal de 1890, en el minúsculo acápite de breve reseña histórica nacional. Sus características son la abreviación y la falta de argumentación científica que es reemplazada por extensas citas de las codificaciones penales ${ }^{73}$. El confinamiento de las citas históricas les permite a estos manualistas del derecho penal hablar con propiedad de los procesos históricos, sin que se tomen el cuidado de cotejar su idea con la realidad empírica ${ }^{74}$. El siguiente es un ejemplo en el que el pasado jurídicopenal colombiano es esquematizado por su autor en tres líneas llenas de ambigüedad y especulación: "Es un derecho fragmentario [el colonial] y sin orientación definida, de aplicación tan solo nominal. Se señalan como características: severidad, arbitrariedad y desigualdad. Representa el traslado de los vejámenes del derecho medieval a América" ${ }^{75}$.Como refutación científica a esta opinión, los avances más destacados en este campo demuestran hechos contrarios, por lo que las ideas expresadas deberían ser matizadas con mayor rigor a la luz de la evidencia histórica ${ }^{76}$.

En suma, en este apartado se han identificado tres fases de la literatura manualística. A ello se añade que la idea de la historia del delito, escrita por los penalistas, sigue las mismas pautas de la progresión histórica de las escuelas penales. En efecto, el resultado de este balance reitera una suerte de principios que han elaborado sociedades en el pasado y que en mayor o menor medida han servido para justificar el presente del derecho penal; además, las pautas de comprensión de la historia del delito siguen apuntando a la legalidad, a la publicidad de las leyes, a la proporcionalidad en los castigos y a la humanización de las penas.

\section{Conclusión}

Como balance final, este texto reitera cómo, pese a un número considerable de obras que constituyen la manualística del derecho penal colombiano, las citas de la historia del delito son exiguas; cunde entre los abogados un anhelo por continuar la creencia en el formalismo y en el legalismo, lo que sumado al influjo de la evolución como categoría historiográfica ha fomentado la opinión de la inutilidad de la historia.

En este trabajo se ha argumentado que las dinámicas pedagógicas del derecho penal han llevado la historia al reduccionismo, a la abstracción y al ejercicio memorístico, así como a la falta de análisis teórico cuando se profundiza en la historia del delito. Este hecho ha configurado la historicidad del delito que se puede encontrar en la tradición manualística y, por tanto, es de igual manera reduccionista. Lo anterior ha significado la exclusión de los contenidos históricos en las explicaciones relacionadas con el crimen; también la visión de la historicidad del delito ha estado cercada por el positivismo, mientras que el origen del fenómeno delictivo ha sido contemplado en perspectiva como la simple violación de la ley positiva. El derecho penal ha dado un viraje a la dogmática penal, lo que hace casi imposible un diálogo con otras explicaciones científicas del delito que no sean jurídicas. En tal sentido, el derecho penal y la idea de la teoría del delito han llenado el contenido de la historia del delito. Es evidente que las circunstancias que motivan alguna reflexión del pasado sean presentistas, pues el motivo de su elaboración son la justificación o crítica a los proyectos de codificación 
de la ley penal, por lo que pocas veces se puede leer la idea de la historia del delito en una investigación de largo aliento.

La incorporación del análisis histórico al quehacer del derecho penal puede contribuir a restituir la matriz de la crítica social ${ }^{77}$, especialmente porque la pedagogía del derecho penal ha retirado el trabajo interdisciplinar de su agenda. De esta manera, el enfoque interdisciplinar de la investigación histórico-jurídica puede incentivar nuevas percepciones de la historicidad delictiva, al debatir qué tan anticuados pueden ser los modelos de aproximación a la historia del delito empleados hasta ahora en la manualística del derecho penal colombiano.

\section{Libros}

ACEVEDO-BLANCO, RAMÓN, Manual de derecho penal (1a ed., Temis, Bogotá, 1983).

ARBOLEDA-VALLEJO, MARIO \& RUIZ-SALAZAR, JOSÉ ARMANDO, Manual de derechopenal (1a ed., Leyer, Bogotá, 2001).

ARENAS, ANTONIO VICENTE, Compendio de derecho penal ( $1^{\text {a }}$ ed., Universidad Nacional de Colombia, Bogotá, 1967).

BARRETO-ROZO, ANTONIO; MALAGÓN-PINZÓN, MIGUEL \& OTERO-CLEVES, ANA MARÍA, Tratados y manuales jurídicos del periodo radical (1ª ed., Uniandes, Bogotá, 2015).

CARREÑO, PEDRO M., Historia y flosofía de la pena (1 ${ }^{a}$ ed., Tipografía del Voto Nacional, Bogotá, 1935).

CEPEDA, CASTOR ANTONIO, Evolución sociológica e histórica de la pena (1ª ed., Editorial Águila, Bogotá, 1935).

CONCHA, JOSÉ VICENTE, Tratado de derecho penal (7a ed., Librería Americana, Bogotá, 1919).

DARWIN, CHARLES, El origen de las especies (1 ${ }^{\text {a }}$ ed., Ediciones Zeus, Barcelona, 1970).

ESCALANTE-BARRETO, ESTANISLAO, Valoración pedagógica de la enseñanza del derecho penal general. Una apuesta por el aprendizaje activo y colaborativo (1ª ed., Universidad Nacional de Colombia, Bogotá, 2016).

FORERO, FELIPE B., El determinismo debe ser la base del derecho penal (1 ${ }^{\text {a }}$ ed., Medardo Rivas, Bogotá, 1892).

GAITÁN-BOHÓRQUEZ, JULIO CÉSAR, Huestes del Estado. La formación universitaria de los juristas en los comienzos del Estado colombiano (1 ${ }^{\mathrm{a}}$ ed., Universidad del Rosario, Bogotá, 2002).

GAITÁN-MAHECHA, BERNARDO, Curso de derecho penal general ( $1^{a}$ ed., Ediciones Lerner, Bogotá, 1967).

GONZÁLEZ-JÁCOME, JORGE, Los debates del pensamiento jurídico colombiano entre 1886 y 1920 (1ª ed., Pontificia Universidad Javeriana, DePalma, Ibáñez, Bogotá, 2015).

GONZÁLEZ-PIEDRAHITA, ERNESTO, Prevención social del crimen (1ª ed., Tipografía Gómez, Bogotá, 1920).

GORDON, SCOTT, Historia y filosofía de las ciencias sociales (1ª ed., Ariel, Barcelona, 1995).

GOYES-MORENO, ISABEL, La enseñanza del derecho en Colombia, 1886-1930 (1ª ed., Universidad de Nariño, Pasto, 2010).

HECKSCHER, ELI, La época mercantilista: historia de la organización y las ideas económicas desde el final de la Edad Media hasta la sociedad liberal (1ª ed., Fondo de Cultura Económica, FCE, México, 1943).

HERZOG, TAMAR, La administración como un fenómeno social. La justicia penal de la ciudad de Quito (1650-1750) (1ª ed., Centro de Estudios Políticos y Constitucionales, CEPC, Madrid, 1995).

IRAGORRI-DÍEZ, BENJAMÍN, Curso de derecho penal general colombiano (1ª ed., Universidad del Cauca, Popayán, 1968).

KENNEDY, DUNCAN, La enseñanza del derecho como forma de acción política (1ª reimp., Siglo XXI, Buenos Aires, 2014).

LÓPEZ-MEDINA, DIEGO EDUARDO, Teoría impura del derecho. La transformación de la cultura jurídica latinoamericana (8a reimp., Universidad Nacional de Colombia, Legis, Uniandes, Bogotá, 2016).

LOZANO Y LOZANO, CARLOS, Elementos de derecho penal (2a ed., Ediciones Lerner, Bogotá, 1961). 
MENDOZA, MANUEL EDMUNDO, La evolución del derecho penal (1 $1^{a}$ ed., Tipografía Hernández O., Cartagena, 1932).

ORTIZ-RODRÍGUEZ, ALFONSO, Manual de derecho penal especial (3ª ed., Universidad de Medellín, Medellín, 1987).

PABÓN-PARRA, PEDRO ALFONSO, Manual de derecho penal (9a ed., Ediciones Doctrina y Ley, Bogotá, 2013). PÁEZ-POLO, ESTEBAN, Nuevo derecho penal colombiano (1 ${ }^{a}$ ed., Ediciones Páez Polo, Barranquilla, 1982).

PAVARINI, MASSIMO, Control y dominación. Teorías criminológicas burguesas y proyecto hegemónico (1ª. ed., Siglo XXI, Buenos Aires, 2003).

PÉREZ, LUIS CARLOS, Derecho penal colombiano. Parte especial, Vol. I (1a ed., Temis, Bogotá, 1953).

PÉREZ, LUIS CARLOS, Derecho penal. Parte general y especial, Tomo I (1 $1^{\text {a }}$ reimp., Temis, Bogotá, 1985).

PÉREZ-PINZÓN, ÁLVARO ORLANDO, Introducción al derecho penal (3a ed., Señal Editora, Medellín, 1989).

QUIJANO, ARTURO, Ensayo sobre la evolución del derecho penal en Colombia (1a ed., Medardo Rivas, Bogotá, 1898). REYES-ECHANDÍA, ALFONSO, Derecho penal (11 a ed., Temis, Bogotá, 2017).

SALVATORE, RICARDO D.; AGUIRRE, CARLOS \& JOSEPH, GILBERT M., eds., Crime and Punishment in Latin America (1st ed., Duke University Press, Durham, 2001).

SEGURA, FERNANDO, Teoría y práctica del derecho penal. Doctrinas y fallos penales (Tipografía del Voto Nacional, Bogotá, 1935).

SEGURA, PABLO, Evolución del derecho penal colombiano (1ª ed., Tipografía Omega, Bogotá, 1924).

SHKLAR, JUDITH N., Legalismo (1ª ed., Bibliográfica Omeba, Buenos Aires, 1968).

SPENCER, HERBERT, Creación y evolución (1ª ed., Sempere \& Cía. Editores, Valencia, 189?).

SPENCER, HERBERT, Principios de sociología, Tomo I (1 $1^{\text {a }}$ ed., Saturnino Calleja, Madrid, 1883).

UMAÑA-LUNA, EDUARDO, La Universidad Nacional en el siglo XIX. Documentos para su historia. Escuela de jurisprudencia ( $1^{a}$ ed., ESTELA RESTREPO-ZEA, comp., Universidad Nacional de Colombia, CES, Bogotá, 2004). Disponible en: http://bdigital.unal.edu.co/1447/

URIBE, ANTONIO JOSÉ, Introducción al estudio del derecho penal. Traducida en parte de la obra de Faustine Hèlie $y$ con datos sobre el derecho penal colombiano (1 $1^{a}$ ed., Librerías de Manuel J. Álvarez C. \& Abraham Moreno \& Hermanos, Medellín, 1890).

VALENCIA-MARTÍNEZ, JORGE ENRIQUE, Derecho penal colombiano, Parte especial (1 ${ }^{\text {a }}$ ed., Ediciones Doctrina y Ley, Bogotá, 2007).

VELÁSQUEZ-VELÁSQUEZ, FERNANDO, Manual de derecho penal (5ª ed., Ediciones Jurídicas Andrés Morales, Bogotá, 2013).

\section{Contribuciones en obras colectivas}

BERGALLI, ROBERTO, Estructura judicial en América Latina, en Pena y estructura social, XVII-XLIV (1st ed., en inglés 1939, GEORG RUSCHE \& OTTO KIRCHHEIMER, eds., $1^{\text {a }}$ ed., Temis, Bogotá, 1984). Disponible en: https://colectivociajpp.files.wordpress.com/2012/08/pena-y-estructura-social-rusche-y-kirchheimer.pdf

BERGALLI, ROBERTO \& BUSTOS-RAMÍREZ, JUAN, Presentación, en Pena y estructura social, XIII-XVI (1st ed., en inglés 1939, GEORG RUSCHE \& OTTO KIRCHHEIMER, eds., 1ª ed., Temis, Bogotá, 1984). Disponible en: https://colectivociajpp.files.wordpress.com/2012/08/pena-y-estructura-social-rusche-y-kirchheimer.pdf

BUSTOS-RAMÍREZ, JUAN, Estructura jurídica y Estado en América Latina, en Pena y estructura social, XLV-LVII (1st ed., en inglés 1939, GEORG RUSCHE \& OTTO KIRCHHEIMER, eds., $1^{\text {a }}$ ed., Temis, Bogotá, 1984). Disponible en: https://colectivociajpp.files.wordpress.com/2012/08/pena-y-estructura-social-rusche-y-kirchh eimer.pdf 
GAITÁN-MAHECHA, BERNARDO, Alfonso Reyes Echandia y el derecho penal colombiano en el siglo veinte, en Dogmática y criminología. Dos visiones complementarias del fenómeno delictivo: homenaje a Alfonso Reyes Echandia, 227-235 (1 $1^{\mathrm{a}}$ ed., Legis, Bogotá, 2005).

GARCÍA-MÉNDEZ, EMILIO, Epilogo a la edición castellana, en Pena y estructura social, 255-270 ( $1^{\text {st }}$ ed. en inglés 1939, GEORG RUSCHE \& OTTO KIRCHHEIMER, eds., $1^{a}$ ed., Temis, Bogotá, 1984).

KENNEDY, DUNCAN, Legal Formalism, en International Encyclopedia of the Social \& Behavioral Sciences, vol. 13, 8634-8638 (1st ed., NEIL J. SMELSER \& PAUL B. BALTES, eds., Elsevier, Amsterdam, Paris, New York, Oxford, Shannon, Singapore, Tokyo, 2001). Disponible en: http://duncankennedy.net/documents/Legal\%20 Formalism.pdf

\section{Revistas}

ARENA, FEDERICO JOSÉ, Formalismos jurídicos e institucionalismo económico. Un análisis filosófico de la critica al formalismo, 3 Revista Telemática de Filosofía del Derecho, RTFD, 185-202 (2010). Disponible en: http://www .rtfd.es/numero13/08-13.pdf

BOURDIEU, PIERRE, Les trois états du capital culturel, 30 Actes de la Recherche en Sciences Sociales, 3-6 (1979). Disponible en: https://www.persee.fr/docAsPDF/arss_0335-5322_1979_num_30_1_2654.pdf

CAYCEDO, BERNARDO J., Discurso del Presidente de la Sociedad Jurídica de la Universidad Nacional sobre la evolución del derecho, 75-76 Revista Jurídica, 331-339 (1916).

ESCOLANO-BENITO, AGUSTÍN, Sobre la construcción histórica de la manualistica en España, XIII Revista Educación y Pedagogía, 29-30, 13-24 (2001). Disponible en: https://aprendeenlinea.udea.edu.co/revistas/inde x.php/revistaeyp/article/viewFile/7503/6906

GÓMEZ-AGUDELO, GUILLERMO ALFONSO, La pedagogia tradicional en las facultades de derecho en Colombia, 5 Via Iuris, 105-109 (2008). Disponible en: https://dialnet.unirioja.es/descarga/articulo/3293490.pdf

JARAMILLO-VÉLEZ, RUBÉN, La filosofía y la provincia. Homenaje a los pioneros del pensamiento moderno en Colombia, 25 Aquelarre, 2, 203-210 (2013). Disponible en: http://ccultural.ut.edu.co/images/Aquelarre\%20N 25\%20T2.pdf

MONROY-CABRA, MARCO GERARDO, Reflexiones sobre la enseñanza del derecho en Colombia, 1 Estudios SocioJurídicos, 1, 162-180 (1999). Disponible en: https://revistas.urosario.edu.co/index.php/sociojuridicos/article/ view/151

PALAO-TABOADA, CARLOS, La enseñanza del derecho en la universidad:presente y futuro, 6 Anuario de la Facultad de Derecho de la Universidad Autónoma de Madrid, AFDUAM, 127-139 (2002). Disponible en: http://afduam .es/wp-content/uploads/pdf/6/6900232-127_140.pdf

PARADA-GARCÍA, GILBERTO ENRIQUE, Sensacionalismo, justicia y gobierno en la prensa neogranadina, 1830-1858, 11 Grafia, 2, 155-175 (2014). Disponible en: http://revistas.fuac.edu.co/index.php/grafia/article/ download/525/503

RUBIO-HERNÁNDEZ, ALFONSO, Los tratados de práctica notarial en las bibliotecas de escribanos neogranadinos del siglo XVIII, 13 Historia y Memoria, 19-46 (2016). Disponible en: https://revistas.uptc.edu.co/index.php/h istoria_memoria/article/view/5198/4371

URÍAS-HORCASITAS, BEATRIZ, El determinismo biológico en México: del darwinismo social a la sociologia criminal, 7 Revista Mexicana de Sociología, 4, 99-126 (1996). DOI: 10.2307/3541043

\section{Working papers}

AGÜERO, ALEJANDRO, El uso del pasado en la enseñanza del derecho penal en Argentina. La imagen del Antiguo Régimen como tradición latente, 4 (Max Planck Institute for European Legal History Research Paper Series, Working Paper No. 2015-07). Disponible en: https://papers.ssrn.com/sol3/papers.cfm?abstract_id=2652713 


\section{Documentos}

ESCALLÓN, RAFAEL, Conferencias de derecho penal dictadas en la Universidad Nacional por el profesor Rafael Escallón (mimeo, 1932).

ESCALLÓN, RAFAEL, Programa de derecho penal para 1935 (Tipografía Voto Nacional, Bogotá, 1935).

GAITÁN, JORGE ELIÉCER, Conferencias de sociología criminal. Dictadas en la Universidad Libre por el Dr. Jorge Eliécer Gaitán (mimeo, 193?).

LOZANO Y LOZANO, CARLOS, Conferencias de derecho penal dictadas por el profesor Carlos Lozano y Lozano en el Externado de Colombia (mimeo, 1950).

\section{Prensa}

GARCÍA-VILLEGAS, MAURICIO, Colombia, tierra de abogados, El Espectador, 1 de mayo de 2010. http://www.e lespectador.com/impreso/nacional/articuloimpreso201004-colombia-tierra-de-abogados. (1o junio, 2017).

\section{Notas}

* Artículo de reflexión.

1 El concepto de la manualística proviene de las ciencias de la educación y consiste en el conjunto de prácticas, diseños, teorías, producción y uso de los manuales de enseñanza. En la tipología de los manuales están los libros de género pedagógico que llevan entre otros los títulos: principios, introducción, nociones, elementos, método, curso, guia, programa y texto. AGUSTÍN ESCOLANOBENITO, Sobre la construcción histórica de la manualistica en España, XIII Revista Educación y Pedagogía, 29-30, 13-24, 19 (2001).

2 La idea de que la historia del derecho penal escrita por los abogados desconoce la realidad contextual es compartida por ALEJANDRO AGÜERO, quien argumenta que para el caso argentino: "Ya sea por ingenuidad o por determinación pragmática o ideológica, esta distancia entre los juristas y los problemas meta-historiográficos, ha facilitado notablemente la reproducción acrítica de unas narrativas históricas en el ámbito de las facultades de derecho que, bajo modestas pretensiones propedéuticas, terminan cumpliendo un papel de solidificación - por repetición - de las propias tradiciones". ALEJANDRO AGÜERO, El uso del pasado en la enseñanza del derecho penal en Argentina. La imagen del Antiguo Régimen como tradición latente (Max Planck Institute for European Legal History Research Paper Series, Working Paper No. 2015-07).

3 ROBERTO BERGALLI, Estructura judicial en América Latina, en Pena y estructura social, XVII-XLIV, XXI (1st ed., en inglés 1939, GEORG RUSCHE \& OTTO KIRCHHEIMER, eds., 1ª ed., Temis, Bogotá, 1984).

4 RICARDO D. SALVATORE, CARLOS AGUIRRE \& GILBERT M. JOSEPH, eds., Crime and Punishment in Latin America, 1-32 ( $1^{\text {st }}$ ed., Duke University Press, Durham, 2001).

5 ESTANISLAO ESCALANTE-BARRETO, Valoración pedagógica de la enseñanza del derecho penal general. Una apuesta por el aprendizaje activo y colaborativo, 24 ( $1^{\text {a }}$ ed., Universidad Nacional de Colombia, Bogotá, 2016).

6 Este influjo se ha hecho sentir en autores que son un referente global. Como ejemplo del sistema relacional mecanicista entre acción y reacción, MASSIMO PAVARINI planteó la criminalización del sindicalismo obrero como un epifenómeno de la lucha de clases, pues durante la industrialización europea, "la reacción en el frente burgués fue inmediata: las asociaciones de trabajadores fueron definidas como asociaciones de malhechores y el proletariado como el potencial criminal. Se conoce así la primera forma de criminalización del adversario de clase". MASSIMO PAVARINI, Control y dominación. Teorias criminológicas burguesas y proyecto hegemónico, 42 (1ª. ed., Siglo XXI, Buenos Aires, 2003). Sin embargo esta explicación mecánica atañe también a los no marxistas, pues el historiador económico de influencia ricardiana ELI HECKSCHER afirmó que el sistema mercantil requirió de una serie de códigos penales que sujetaron la mano con fines capitalistas. ELI HECKSCHER, La época mercantilista: historia de la organización y las ideas económicas desde el final de la Edad Media hasta la sociedad liberal (1 $1^{\mathrm{a}}$ ed., Fondo de Cultura Económica, FCE, México, 1943). 
7 DUNCAN KENNEDY, Legal Formalism, en International Encyclopedia of the Social \& Behavioral Sciences, vol. 13, 8634-8638 ( $1^{\text {st }}$ ed., NEIL J. SMELSER \& PAUL B. BALTES, eds., Elsevier, Amsterdam, Paris, New York, Oxford, Shannon, Singapore, Tokyo, 2001).

8 DIEGO EDUARDO LÓPEZ-MEDINA, Teoria impura del derecho. La transformación de la culturajurídica latinoamericana, 130 (8a reimp., Universidad Nacional de Colombia, Legis, Uniandes, Bogotá, 2016).

9 FEDERICO JOSÉ ARENA, Formalismos jurídicos e institucionalismo económico. Un análisis filosófico de la crítica al formalismo, 3 Revista Telemática de Filosofia del Derecho, RTFD, 185-202, 186-188 (2010).

10 FEDERICO JOSÉ ARENA, Formalismos jurídicos e institucionalismo económico..., 185-202, 187 (2010).

11 JUDITH N. SHKLAR, Legalismo, 47 (1ª ed., Bibliográfica Omeba, Buenos Aires, 1968).

12 JUDITH N. SHKLAR, Legalismo, 69 (1968). En la década de 1980, JUAN BUSTOS-RAMÍREZ también planteó esta idea sobre el legalismo para el caso de América Latina: "El derecho y la ley aparecen como una actividad desligada de la relación social concreta, como un ámbito propio ajeno a una sociedad determinada, y más bien, como el esquema ideal de un determinado sistema global: el de la sociedad burguesa". JUAN BUSTOS-RAMÍREZ, Estructura jurídica y Estado en América Latina, en Pena y estructura social, XLV-LVII, LII ( $1^{\text {st }}$ ed., en inglés 1939, GEORG RUSCHE \& OTTO KIRCHHEIMER, eds., $1^{\text {a }}$ ed., Temis, Bogotá, 1984).

13 DIEGO EDUARDO LÓPEZ-MEDINA, Teoria impura del derecho. La transformación de la cultura jurídica latinoamericana, 118-119 (2016).

14 ISABEL GOYES-MORENO, La enseñanza del derecho en Colombia, 1886-1930, 255-256, 258 (1ª ed., Universidad de Nariño, Pasto, 2010).

15 ALFONSO RUBIO ha investigado la formación de los escribanos - el equivalente a los notarios actuales - durante el siglo XVIII neogranadino y concluye que ese oficio — que era eminente jurídico- fue un producto más de la formación práctica que de la preparación intelectual. Ello se debió a la inexistencia de libros teóricos; por el contrario, los escribanos acudían a un reducido número de manuales y formularios, ninguno publicado localmente, que mediaban las convenciones propias de su oficio. ALFONSO RUBIO-HERNÁNDEZ, Los tratados depráctica notarial en las bibliotecas de escribanos neogranadinos del siglo XVIII, 13 Historia y Memoria, 19-46, 30 (2016).

16 MARCO GERARDO MONROY-CABRA, Reflexiones sobre la enseñanza del derecho en Colombia, 1 Estudios SocioJurídicos, 1, 162-180, 169 (1999).

17 En cuanto al dictado, JULIO GAITÁN-BOHÓRQUEZ argumenta que se consolidó desde el período colonial debido al escaso número de libros jurídicos que circulaban en el contexto neogranadino. JULIO CÉSAR GAITÁN-BOHÓRQUEZ, Huestes del Estado. La formación universitaria de los juristas en los comienzos del Estado colombiano, 115, 116 (12 ed., Universidad del Rosario, Bogotá, 2002).

18 ISABEL GOYES-MORENO, La enseñanza del derecho en Colombia, 1886-1930, 156 (1ª ed., Universidad de Nariño, Pasto, 2010).

19 GUILLERMO ALFONSO GÓMEZ-AGUDELO, La pedagogia tradicional en las facultades de derecho en Colombia, 5 Via Iuris, 105-109, 107 (2008).

20 DIEGO EDUARDO LÓPEZ-MEDINA, Teoría impura del derecho. La transformación de la cultura jurídica latinoamericana, 2 (2016). DUNCAN KENNEDY, La enseñanza del derecho como forma de acción política, 35 (1ª reimp., Siglo XXI, Buenos Aires, 2014).

21 CARLOS PALAO-TABOADA, La enseñanza del derecho en la universidad: presente y futuro, 6 Anuario de la Facultad de Derecho de la Universidad Autónoma de Madrid, AFDUAM, 127-139, 128 (2002).

22 Carlos Palao Taboada, La enseñanza del derecho en la universidad: presente y futuro. Anuario de la Facultad de Derecho de la Universidad Autónoma de Madrid, 6, 127-128 (2002).

23 PIERRE BOURDIEU, Les trois états du capital culturel, 30 Actes de la Recherche en Sciences Sociales, 3-6, 3 (1979).

24 PIERRE BOURDIEU, Les trois états du capital culturel, 30 Actes de la Recherche en Sciences Sociales, 3-6, 4 (1979). 
25 ANTONIO BARRETO-ROZO, MIGUEL MALAGÓN-PINZÓN \& ANA MARÍA OTERO-CLEVES, Tratados $y$ manuales jurídicos del período radical ( $1^{\text {a }}$ ed., Uniandes, Bogotá, 2015).

26 Una idea afirma que el positivismo penal buscó en la antropología y en la sociología un argumento teórico y metodológico, pero descartó el análisis histórico por el criterio que da mayor peso al estudio del derecho positivo que a la reflexión histórica de la ley penal. RAFAEL ESCALLÓN, Conferencias de derecho penal dictadas en la Universidad Nacional por el profesor Rafael Escallón, 26 (mimeo, 1932). De igual manera, a inicios del siglo XX, había un llamado para que la actividad intelectual del derecho en Colombia no se redujera a "[...] mirar las glorias pasadas, sino que se apreste a merecer las venideras". BERNARDO J. CAYCEDO, Discurso del Presidente de la Sociedad Jurídica de la Universidad Nacional sobre la evolución del derecho, 75-76 Revista Jurídica, 331-339, 339 (1916).

27 "El profundo y total desenmascaramiento que del positivismo ha efectuado lo que se denomina una \#criminología crítica\#, ha transformado la aproximación a los problemas en una obligada relación histórica entre el fenómeno y los ámbitos social, político y económico en que se manifiesta". ROBERTO BERGALLI \& JUAN BUSTOS-RAMÍREZ, Presentación, en Pena y estructura social, XIII-XVI, XIV ( $1^{\text {st }}$ ed., en inglés 1939, GEORG RUSCHE \& OTTO KIRCHHEIMER, eds., $1^{a}$ ed., Temis, Bogotá, 1984).

28 CARLOS LOZANO Y LOZANO, Conferencias de derecho penal dictadas por el profesor Carlos Lozano y Lozano en el Externado de Colombia, 3 (mimeo, 1950).

29 La selección natural fue argumentada por Charles Darwin en La selección natural; o la supervivencia de los más aptos, cuarto capítulo de su libro El origen de las especies, publicado por vez primera en 1859. CHARLES DARWIN, El origen de las especies, 89-138 (1 $1^{\text {a }}$ ed., Ediciones Zeus, Barcelona, 1970).

30 "El interés que ha suscitado esta cuestión reside en el hecho de que la ciencia contemporánea no ha renunciado a la búsqueda de los determinantes biológicos que expliquen el sentido de ciertos fenómenos y conductas antisociales". BEATRIZ URÍAS-HORCASITAS, El determinismo biológico en México: del darwinismo social a la sociología criminal, 7 Revista Mexicana de Sociologia, 4, 99-126, 100 (1996). DOI: 10.2307/3541043

31 "Spencer, Durkheim y Weber definieron con eficacia, en sus importantes estudios del comportamiento social y en sus amplios análisis de la metodología, la materia temática de la sociología moderna y desarrollaron muchos de los conceptos que han considerado útiles desde entonces los sociólogos en la investigación teórica y empírica". SCOTT GORDON, Historia y filosofia de las ciencias sociales, 444 (1 $1^{\mathrm{a}} \mathrm{ed} .$, Ariel, Barcelona, 1995).

32 HERBERT SPENCER, Principios de sociologia, Tomo I, 13 (1 $1^{\mathrm{a}} \mathrm{ed}$., Saturnino Calleja, Madrid, 1883).

33 HERBERT SPENCER, Creación y evolución, 26 (1ª ed., Sempere \& Cía. Editores, Valencia, 189?).

34 HERBERT SPENCER, Creación y evolución, 98 (189?).

35 ARTURO QUIJANO, Ensayo sobre la evolución del derecho penal en Colombia, 14 (1 ${ }^{\mathrm{a}}$ ed., Medardo Rivas, Bogotá, 1898).

36 BERNARDO J. CAYCEDO, Discurso del Presidente de la Sociedad Jurídica de la Universidad Nacional sobre la evolución del derecho, 75-76 Revista Juridica, 331-339, 335 (1916).

37 PABLO SEGURA, Evolución del derecho penal colombiano (1ª ed., Tipografía Omega, Bogotá, 1924).

38 ERNESTO GONZÁLEZ-PIEDRAHITA, Prevención social del crimen, 17 (1 $1^{\text {a }}$ ed., Tipografía Gómez, Bogotá, 1920).

39 JORGE ELIÉCER GAITÁN, Conferencias de sociología criminal. Dictadas en la Universidad Libre por el Dr. Jorge Eliécer Gaitán, 4 (mimeo, 193?).

40 RAFAEL ESCALLÓN, Conferencias de derecho penal dictadas en la Universidad Nacional por el profesor Rafael Escallón, 4 (mimeo, 1932).

41 PEDRO M. CARREÑO, Historia y flosofía de la pena, 7 (1ª ed., Tipografía del Voto Nacional, Bogotá, 1935).

42 CASTOR ANTONIO CEPEDA, Evolución sociológica e histórica de la pena, 13 (1ª ed., Editorial Águila, Bogotá, 1935).

43 FELIPE B. FORERO, El determinismo debe ser la base del derecho penal, 11-12 (1ª ed., Medardo Rivas, Bogotá, 1892). 
44 En este sentido, el abogado MANUEL EDMUNDO MENDOZA explicaba cómo el derecho penal se convertía el parteaguas de un estado de salvajismo criminal: "El crimen no es más que el retroceso, por un fenómeno de psicología retrógrada, y por un acto involuntario, ocasionado por la palpitación del accidente morfológico, a una época precaria de la civilización, cuando el hombre tenía en su alma el tosco lineamiento de la Edad de Piedra, y el criminal un salvaje surgido de improviso, por el poder de fuerzas inestables de la naturaleza corporal en medio de la sociedad moderna. En la formación del hombre delincuente, los sedimentos etnográficos van acumulando lentamente su grano de arena, hasta el día en que presentan frente a Código toda una torva colina de imperfecciones morales, capaces de turbar la tranquilidad social”. MANUEL EDMUNDO MENDOZA, La evolución del derecho penal, 7 (1 $1^{\text {a }}$ ed., Tipografía Hernández O., Cartagena, 1932).

45 "Entre 1993 y 2001 hubo en Colombia un crecimiento espectacular del número de facultades de Derecho y ello debido, sobre todo, a los incentivos creados por la ley 30 de 1992 para la creación de programas de educación superior. Mientras que en 1993 había 32 universidades que ofrecían esta carrera, en 2001 ese número ascendió a 63 y en 2007 a 72 . Más impresionante es el crecimiento de los programas de Derecho - una misma facultad puede ofrecer varios_, que pasaron de cerca de 60 en 1993 a 178 en 2007 ". MAURICIO GARCÍA-VILLEGAS, Colombia, tierra de abogados, El Espectador, 1 de mayo de 2010. Disponible en: http://ww w.elespectador.com/impreso/nacional/articuloimpreso201004-colombia-tierra-de-abogados

46 FERNANDO VELÁSQUEZ-VELÁSQUEZ, Manual de derecho penal, 232 ( 5 a ed., Ediciones Jurídicas Andrés Morales, Bogotá, 2013).

47 JOSÉ VICENTE CONCHA, Tratado de derecho penal, 5 (7 a ed., Librería Americana, Bogotá, 1919). Otro manual destacado que aparece en la década de 1890 es el de ANTONIO JOSÉ URIBE. ANTONIO JOSÉ URIBE, Introducción al estudio del derecho penal. Traducida en parte de la obra de Faustine Hèlie y con datos sobre el derecho penal colombiano ( $1^{\mathrm{a}}$ ed., Librerías de Manuel J. Álvarez C. \& Abraham Moreno \& Hermanos, Medellín, 1890).

48 En 1967 fue publicado un manual que se propuso brindar a los estudiantes de derecho una visión "rápida y global" de todos los conocimientos de derecho penal, impartidos en el transcurso de varios años. Lo anterior con el fin de superar los exámenes preparatorios. ANTONIO VICENTE ARENAS, Compendio de derecho penal, IX (1 $1^{\text {a }}$ ed., Universidad Nacional de Colombia, Bogotá, 1967).

49 EDUARDO UMAÑA-LUNA, La Universidad Nacional en el siglo XIX. Documentos para su historia. Escuela de jurisprudencia, 14 (1 $1^{\text {a }}$ ed., ESTELA RESTREPO-ZEA, comp., Universidad Nacional de Colombia, CES, Bogotá, 2004).

50 RUBÉN JARAMILLO-VÉLEZ, La filosofía y la provincia. Homenaje a los pioneros del pensamiento moderno en Colombia, 25 Aquelarre, 2, 203-210, 208 (2013).

51 JORGE GONZÁLEZ-JÁCOME, Los debates del pensamiento jurídico colombiano entre 1886 y 1920, 34 (1ª ed., Pontificia Universidad Javeriana, DePalma, Ibáñez, Bogotá, 2015).

52 "El derecho definió como ninguna otra profesión la personalidad urbana de muchos bogotanos y en general de los colombianos pertenecientes a la élite. La Nueva Granada fue proyectada por y para los abogados; aun en corrientes partidistas antitéticas, los arquitectos de la República fueron abogados o estudiaron derecho. [...]”. GILBERTO ENRIQUE PARADA-GARCÍA, Sensacionalismo, justicia y gobierno en la prensa neogranadina, 1830-1858, 11 Grafía, 2, 155-175, 164 (2014).

53 EDUARDO UMAÑA-LUNA, La Universidad Nacional en el siglo XIX. Documentos para su historia. Escuela de jurisprudencia, 17 (2004).

54 Dos referencias atestiguan este argumento. La primera es afirmar, sin mayor sustento, que las sociedades del pasado no conocieron la función penal, ya que "no existió en los pueblos primitivos". La segunda tiene qué ver con el autorreconocimiento del derecho penal como ciencia en el siglo XIX. MARIO ARBOLEDA-VALLEJO \& JOSÉ ARMANDO RUIZ-SALAZAR, Manual de derecho penal (1 $1^{\text {a }}$ ed., Leyer, Bogotá, 2001).

55 En 1935, el magistrado FERNANDO SEGURA publicó un manual dirigido a los abogados, a los estudiantes de derecho y a los jueces con el cual pretendió nutrir la literatura jurídica en los campos de la teoría y la práctica penal. Este manual puso de relieve el análisis etimológico del concepto del delito y el de sus categorías tipificadas en Colombia, para lo cual subordinó el relato histórico del delito a su entendido etimológico. FERNANDO SEGURA, Teoría y práctica del derecho penal. Doctrinas y fallos penales (Tipografía del Voto Nacional, Bogotá, 1935).

56 FERNANDO VELÁSQUEZ-VELÁSQUEZ, Manual de derecho penal, 234 ( 5 a ed., Ediciones Jurídicas Andrés Morales, Bogotá, 2013). 
57 El siguiente pasaje ilustra el tono copista y comentarista de la ley que profesan algunos abogados: "Reducido por propia decisión al comentario y a la exégesis de la parte especial, con la debida lealtad quiero consagrar este quehacer intelectual a quienes se inician en el campo de derecho penal, y así, estos textos de estudio serán tanto míos, como de quienes se acerquen a ellos".JORGE ENRIQUE VALENCIA-MARTÍNEZ, Derecho penal colombiano, Parte especial, 2 (1ª ed., Ediciones Doctrina y Ley, Bogotá, 2007).

58 CARLOS LOZANO Y LOZANO, Elementos de derecho penal, 117 (2a ed., Ediciones Lerner, Bogotá, 1961).

59 PEDRO ALFONSO PABÓN-PARRA, Manual de derecho penal, Tomo I, 5 (9a ed., Ediciones Doctrina y Ley, Bogotá, 2013).

60 BENJAMÍN IRAGORRI-DÍEZ, Curso de derecho penal general colombiano, 2 ( $1^{\text {a }}$ ed., Universidad del Cauca, Popayán, 1968).

61 ESTEBAN PÁEZ-POLO, Nuevo derecho penal colombiano, 48 (1ª ed., Ediciones Páez Polo, Barranquilla, 1982).

62 Esta misma estructura de contenidos se repetía en los cursos de derecho. RAFAEL ESCALLÓN, Programa de derecho penal para 1935, 3-7 (Tipografía Voto Nacional, Bogotá, 1935).

63 CARLOS LOZANO Y LOZANO, Elementos de derecho penal, VII (1961).

64 JOSÉ VICENTE CONCHA, Tratado de derecho penal (7a ed., Librería Americana, Bogotá, 1919).

65 BERNARDO GAITÁN-MAHECHA, Alfonso Reyes Echandía y el derecho penal colombiano en el siglo veinte, en Dogmática y criminologia. Dos visiones complementarias del fenómeno delictivo: homenaje a Alfonso Reyes Echandia, 227-235, 227 (1ªd., Legis, Bogotá, 2005).

66 LUIS CARLOS PÉREZ, Derecho penal colombiano. Parte especial, Vol. I, vii-viii (1ª ed., Temis, Bogotá, 1953).

67 El tono de censura que PÉREZ propuso en su Derecho penal, especialmente las ideas en torno a su crítica antidogmática de la teoría del delito - en lo referente a la noción de la acción - fue tema de discusión en trabajos posteriores como el Curso de derecho penal general, publicado por GAITÁN-MAHECHA en 1967. BERNARDO GAITÁN-MAHECHA, Curso de derecho penal general, 97-100 (1ª ed., Ediciones Lerner, Bogotá, 1967).

68 LUIS CARLOS PÉREZ, Derecho penal. Parte general y especial, Tomo I (1ª reimp., Temis, Bogotá, 1985).

69 LUIS CARLOS PÉREZ, Derecho penal. Parte general y especial, Tomo I, 23 (1ª reimp., Temis, Bogotá, 1985).

70 ALFONSO REYES-ECHANDÍA, Derecho penal, 12 (11 ed., Temis, Bogotá, 2017).

71 ÁLVARO ORLANDO PÉREZ-PINZÓN, Introducción al derecho penal, 53-81 (3ª ed., Señal Editora, Medellín, 1989).

72 RAMÓN ACEVEDO-BLANCO, Manual de derecho penal, VI (1a ed., Temis, Bogotá, 1983).

73 ALFONSO ORTIZ-RODRÍGUEZ, Manual de derecho penal especial (3a ed., Universidad de Medellín, Medellín, 1987).

$74 \mathrm{Al}$ respecto, LOZANO Y LOZANO se pronunció contra el carácter libresco de la investigación jurídico penal colombiana a mediados del siglo XX: "La época actual no puede contentarse con sistemas elaborados en el callado recinto de una biblioteca, fuera de las palpitaciones aceleradas de la vida social". CARLOS LOZANO Y LOZANO, Conferencias de derecho penal dictadas por el profesor Carlos Lozano y Lozano en el Externado de Colombia, 2 (mimeo, 1950).

75 PEDRO ALFONSO PABÓN-PARRA, Manual de derecho penal, 73 (2013).

76 Las investigaciones interdisciplinares en este tema reconsideran los sesgos historiográficos, con advertencias sobre el método pues sobrepasan la lectura canónica de las normas penales, procesales y los expedientes para reafirmar un proceso de creación, en torno a las ideas de la justicia y del derecho. "La ley parecía ser un instrumento en un juego social cuya lógica se encontraba lejana del mundo del derecho". TAMAR HERZOG, La administración como un fenómeno social. La justicia penal de la ciudad de Quito (1650-1750), 19 (1ª ed., Centro de Estudios Políticos y Constitucionales, CEPC, Madrid, 1995).

77 EMILIO GARCÍA-MÉNDEZ, en el epílogo en castellano del libro Pena y estructura social, señalaba hace más de treinta años que: "existe un elemento que puede y debe ser incorporado de manera incuestionable en el contexto latinoamericano: la recuperación de la dimensión histórica de la cuestión criminal”. EMILIO GARCÍA-MÉNDEZ, Epílogo a la edición castellana, 
Gilberto Enrique Parada-García. La historicidad del delito en la manualística del derecho penal co...

en Pena y estructura social, 255-270, 270 ( $1^{\text {st }}$ ed. en inglés 1939, GEORG RUSCHE \& OTTO KIRCHHEIMER, eds., $1^{\text {a }}$ ed., Temis, Bogotá, 1984).

Licencia Creative Commons CC BY 4.0

Para citar este articulo/To cite this article: Parada-García, Gilberto Enrique, La historicidad del delito en la manualistica del derecho penal colombiano, 137 Vniversitas, $\mathrm{xx}-\mathrm{xx}$ (2018). https://doi.org/10.11144/Javeria na.vj137.hdmp 